\title{
VOLUME PERCENTAGE OF PETUNG BAMBOO (DENDROCALAMUS ASPER) WOVEN STRIPAS A REINFORCEMENTOF EPOXY RESIN COMPOSITES TO THE TENSILE STRENGTH
}

\author{
FRANS ROBERT BETHONY ${ }^{1}$, HAMMADA ABBAS ${ }^{2}$, ZULKIFLI DJAFAR $^{3}$, MUHAMMAD SYAHID ${ }^{4}$, \\ \& OBETRANTEALLO 5 \\ ${ }^{I}$ TorajaIndonesia Christian University; Mechanical Engineering Faculty, Tana Toraja, South Sulawesi, Indonesia \\ ${ }^{2,3,4}$ Hasanuddin University, Departement of Engineering Faculty, Makassar, South Sulawesi, Indonesia
}

Received: Jun 09, 2020; Accepted: Jun 29, 2020; Published: Aug 07, 2020; Paper Id.: IJMPERDJUN2020685

\section{INTRODUCTION}

Bamboo is one of the natural materials that have prospects good enough to be used as a reinforcing material composite material. The availability of bamboo plants in various parts of Indonesia is relatively abundant, not least in South Sulawesi province in general, and in the Toraja region in particular. To improve and empower the utilization of bamboo, especially the kind petungbamboo (Dendrocalamus asper) who had only used as building materials and crafts, converted into an engineering material, it needs to be researched and developed as a reinforcing material for composite materials by the mechanical properties, that will create a composite new material.

The new composite material, always demanded not only superior in terms of utilization but also expected to environmentally friendly and even recyclable and killed itself naturally. Many nations in the world are now working to create environmentally friendly products without forgetting the original purpose of the product is created.

With the existence of these demands, the development of engineering technology composite material natural ingredients are now beginning to be taken into account, especially in the time of industrialization competition today. Several studies have been conducted by researchers earlier showed that the composite material products are to 
brace natural ingredients that have been able to compete with products made from metal.

Some previous studies that utilize fiber or strip of bamboo, first performed the initial treatment to obtain better mechanical properties for subsequent use as a reinforcing material in the composite material. Materials used in the initial treatment generally using elemental or chemical solutions on the market. While the research by using materials such as sulfur water pretreatment against petung bamboo woven strips have not been done to date.

Until now, no studies using strip-shaped petung with sulfur water to marinade material as a reinforcing material composite.

Composite is a material formed from a combination of two or more constituent materials with the inhomogeneous mixture, wherein the mechanical properties of each of the different constituent materials. The mixture will be produced from a composite material that has mechanical properties and the different characteristics of the constituent material.

The composite material has the properties of conventional materials are generally of the manufacturing process of the mixing is not homogeneous, so freely plotting the desired strength composite material by regulating the composition of the constituent material. Because the fibers used as reinforcement of composites, the fiber will determine the characteristics of composite materials, such as stiffness, strength, and mechanical properties of the other. Fiber who hold the majority of the forces acting on the composite material, while the matrix serves to protect and bind the fibers to work properly.

One advantage of composite materials is the ability of the material to be directed so that the strength can be set only in a specific direction at will. This is called tailoring properties and this is one of the special properties of composites as compared to other conventional material. In addition to a stronger, stiffer and lighter composite has a high resistance also to dynamic loads. Therefore, the material used fiber material is strong, rigid, and brittle, while the load matrix selected materials and soft clay. Additionally, another advantage of the use of composites, among others, lightweight, corrosionresistant, tired.

Composites and alloys have the distinction of how the merger ie when combined macroscopic composite brings up the fiber and the matrix (composite fiber) while the alloy or alloy microscopically merged so as not to be seen again supporting elements. work properly.

The material properties result of the merger is expected to complement the weaknesses that exist in each of its constituent materials. The properties that can be updated include :

One advantage of composite materials is the ability of the material to be directed so that the strength can be set only in a specific direction at will. This is called tailoring properties and this is one of the special properties of composites as compared to other conventional material. In addition to a stronger, stiffer and lighter composite has a high resistance also to dynamic loads. Therefore, the material used fiber material is strong, rigid, and brittle, while the load matrix selected materials and soft clay. Additionally, another advantage of the use of composites, among others, lightweight, corrosionresistant, tired.

Composites and alloys have the distinction of how the merger ie, when combined macroscopic composite brings up the fiber and the matrix (composite fiber) while the alloy or alloy microscopically merged so as not to be seen again supporting elements. work properly. 
The material properties result of the merger is expected to complement the weaknesses that exist in each of its constituent materials. The properties that can be updated includea Strength is a material's ability to withstand the load without fracture.

- The rigidity (stiffness), which is something that can not be separated from the material. Many of rigid material having a low density to restrain deformation of the installation, gravity, and vibration during operation.

- The corrosion resistance (Corrosion Resistance) that is not quickly corroded so discount long-time service life,

- Weight (Weight) is the weight of the material that can be turned into light without reducing its elements.

- $\quad$ Resilience tired (Fatigue Life), a phenomenon of the occurrence of material damage due to repetitive loading. If the material is subjected to repetitive stress, it will be broken at voltages much lower than the voltage needed to cause fractures of the static load.

- The thermal conductivity, which increases the rate of heat propagation in solids with a stream flowing from the higher temperature to low.

In general, the properties of the composite is determined by several factors, among others :

- The type of constituent materials, namely yan fiber material will be used like coco fiber, palm fiber, pineapple fiber, banana fiber, and others.

- the geometric shape and structure of the constituent materials, the form of fibers, cracks, and the structure of the constituent materials in the manufacture of composite materials.

- The ratio of constituent materials, the ratio of materials to be used to produce new composite materials, and good.

- the adhesion between the constituent materials, the fiber's ability to bind to each other between the constituent materials.

- The process of making, in this process, to consider steps to create new material to obtain good material and by the standards.

Industrial progress based composite material in particular synthetic materials has been growing rapidly. While the use of natural materials as the base material is still small. Though nature provides cheap and abundant materials to be developed into various products. Composite is a material consisting of two or more different materials that form a unity. Application of these composites includes: wall panels, Elavon, tiles are reinforced with fibers (FRC-fiber reinforced concrete) are now widely used in buildings.

Composite natural material has a distinctive among other renewable, environmentally friendly (degraded), and low prices. While difficult degradable synthetic fibers, produces CO and dust is harmful to health if recycled. Polymerbased materials have high corrosion resistance in an acidic environment (chlorine). But the polymer material has a relatively low mechanical strength because it required fiber (fiber) as a composite amplifier.

Corrosion resistance properties of a high polymer combined with the mechanical strength of the fiber (fiber) is one of the selling points of the polymer matrix composite material. While the fiber as a reinforcing element largely determines the mechanical properties of composites because of the continuing burden is distributed by the matrix. Factors 
affecting the mechanical properties of the lamina include orientation, size, and shape of the fibers. Natural fibers combined with resin as the matrix will produce a composite alternative with the varying direction of orientation of natural fibers (Figure 1) so that the expected result that the maximum mechanical strength composites.

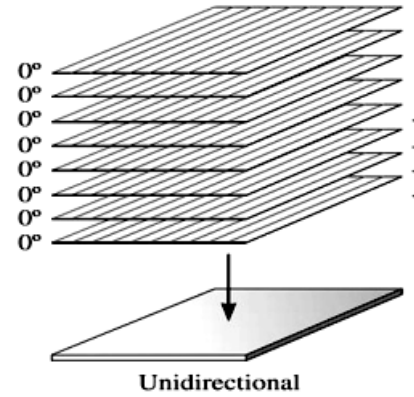

(a)

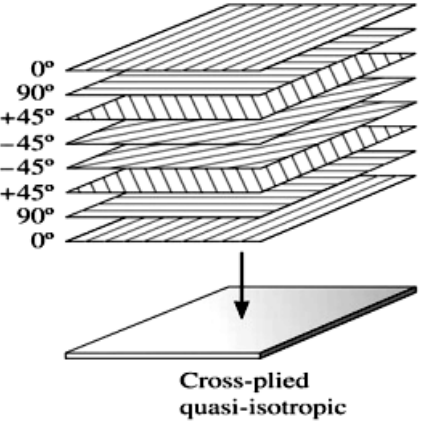

(b)

Figure 1: The Direction Orientation on FRP Composites, (a) Unidirectional (b) Quasiisotropic.

Composite is a merger of two or more macroscopic material between the fibers and the matrix. Macroscopic showed that the material forming the composite still looks like the original, as opposed to the incorporation of the alloy via homogeneous melting solidification process, the constituent material is not seen again. The purpose of the merger is not only to obtain the addictive properties of the constituent material but mainly to gain synergetic nature (Gibson, 1994).

Serves to strengthen the matrix fibers because the fiber is generally much stronger than the matrix. The matrix serves to protect the fiber from environmental influences and damage from the impact. While broadly there are three types of composite fiber-reinforced polymer (FRP) based amplifiers (fiber) used (figure 2). Fiber composites (fibrous composites) consists of one lamina (layers) that use an amplifier in the form of fiber (fiber), which are arranged randomly or with a certain orientation direction even in more complex forms such as woven. Composite particles (particulate composites) using particles (powder) as a reinforcement and distributed uniformly in the matrix. And the composite laminate (laminated composites) composites that consist of two or more layers are merged into one, and each layer has its characteristics (Morissco, 1999).
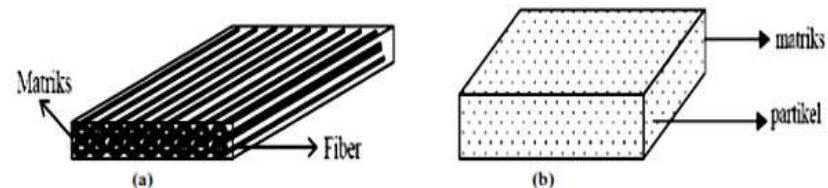

(b)

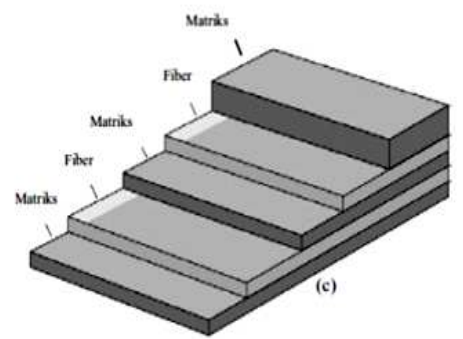

Figure 2: Type Composite (a) Composite Fibers, (b) A Composite Particle

(c) The Composite Laminate.

The mechanical properties of petungbamboo wovenstrips influenced by the number of cellulose molecules contained therein, which is closely related to the crystallinity of woven strips and microfibril angle to the principal axis of woven strips. The greater the content therein Cellulosa more opportunities to interact to form strong hydrogen bonds along 
with the chain cellulose.

If given a treat with a great concentration of sulfur water, in particular, will lead to a strong molecular bond along the cellulose chain, cohesion, and adhesion properties or surface properties of woven strips wettability will increase.

With sulfurwater treatment on the surface, then the surface will change the form of woven strips formation of pores thus increasing the surface area of woven strips, strips of woven surface shape will be more crystallized and more regular and woven strip surface will be smooth. Improved surface properties of woven strips will be increased in line with the increasing concentration of sulfur and old water treatment to be given to it.

The result is a single strip of webbing mechanical properties will increase, as well as an increase in the shear strength of the fiber-matrix interface. Another impact is no less important is the increased surface area of woven strips then the quantity of epoxy resin that seeped into the surface of the strip of webbing is growing and reach the entire surface of the woven strips thus improving mechanical properties

If the treatment using sulfur water, there will be a faster reaction rate and the distance between the molecules to be short. This allows a high cohesion occurs on the surface of woven strips and eventually impacts on improving the mechanical properties of woven strips.

The tensile strength can be enhanced by using a strip of woven surface treatment of sulfur water marinade ingredients.

Immersion in the sulfur water is intended will increase the wettability properties of woven strips so that a separate phase between the strip and the matrix can be minimized. Also, immersion in water sulfur will remove impurities and bacteria and lignin that attach to the surface of the strip of webbing.

The result is a strip woven surface will be smooth and wide contact area with the epoxy resin woven strips will be on the increase. Besides molecules in woven strips collide with molecules in sulfur water would occur given the strong hydrogen bonding to the surface of woven strips.

By knowing the magnitude of the characteristics of the mechanical properties of the composite epoxy resin that occurs, then discovered the ability of epoxy resin reinforced composite petung bamboo woven strips.

\section{METHODS}

Materials to be used in research are:

- Petung bamboo in strips.

- Ingredients marinade: sulfur water.

- Epoxy resin.

With a treatment method in which the material petung bamboo strip woven by immersion in sulfur water taken from a mountain in the Toraja area conducted over four weeks. The shape of the matrix petung bamboo is a form of a strip with a variation of the strip volume fraction of $20 \%, 40 \%, 60 \%$ strip petung bamboo woven strip. The mechanical properties petung bamboo woven strip are the amount of strength that occurs in the treated woven strip after immersion in sulfur water. Mechanic properties of the composite epoxy resin-petung bamboo woven strip is the ability of the composite 
withstand the force/external loads imposed on the composite material, in this case, is the length of the material tensile test with $63 \mathrm{~mm}$.

Decision-water immersion, in a Makula', as a source of sulfur water in mountainous regions district of Tana Toraja. Testing of mechanical research in this case the tensile test was conducted in the Laboratory of Physical Metallurgy, Mechanical Engineering, Faculty of Engineering, University of Hasanuddin.

\section{RESULTS}

Table 1: Results of Tensile Test for Petungbamboo Wovenstrip $20 \%$ after Immersion in Sulfurwater

\begin{tabular}{|c|c|c|c|c|c|c|c|c|c|}
\hline \multicolumn{10}{|c|}{ Woven Strip 20\% } \\
\hline \multicolumn{10}{|c|}{ Specimen } \\
\hline \multicolumn{3}{|c|}{1} & \multicolumn{2}{|r|}{2} & \multicolumn{2}{|r|}{3} & \multicolumn{2}{|r|}{4} & \\
\hline w & 22 & \multirow{2}{*}{$0=63 \mathrm{~mm}$} & 21,4 & \multirow{2}{*}{$0=63 \mathrm{mn}$} & 22 & \multirow{2}{*}{$0=63 \mathrm{mn}$} & 21,5 & \multirow{2}{*}{$0=63 \mathrm{mn}$} & \\
\hline $\mathbf{t}$ & 5 & & 6 & & 5,5 & & 6 & & \\
\hline$\Delta \mathbf{L}$ & $\mathbf{F}(\mathbf{N})$ & $\sigma$ & $F(\mathbf{N})$ & $\boldsymbol{\sigma}$ & $F(\mathbf{N})$ & $\boldsymbol{\sigma}$ & $\mathbf{F}(\mathbf{N})$ & $\boldsymbol{\sigma}$ & $\boldsymbol{\varepsilon}$ \\
\hline 0,50 & 200 & 1,818 & 100 & 0,779 & 190 & 1,570 & 100 & 0,775 & 0,794 \\
\hline 1,00 & 650 & 5,909 & 500 & 3,894 & 650 & 5,372 & 550 & 4,264 & 1,587 \\
\hline 2,00 & 1050 & 9,545 & 1000 & 7,788 & 1040 & 8,595 & 980 & 7,597 & 3,175 \\
\hline 2,50 & 1650 & 15,000 & 1600 & 12,461 & 1600 & 13,223 & 1580 & 12,248 & 3,968 \\
\hline 3,00 & 2250 & 20,455 & 2200 & 17,134 & 2240 & 18,512 & 2100 & 16,279 & 4,762 \\
\hline 3,50 & 2750 & 25,000 & 2650 & 20,639 & 2700 & 22,314 & 2600 & 20,155 & 5,556 \\
\hline 4,00 & 3250 & 29,545 & 2850 & 22,196 & 3230 & 26,694 & 2750 & 21,318 & 6,349 \\
\hline
\end{tabular}

Table 2: Results of Tensile test for Petungbamboo Wovenstrip40\% after Immersion in Sulfurwater

\begin{tabular}{|c|c|c|c|c|c|c|c|c|c|}
\hline \multicolumn{10}{|c|}{ Woven Strip 40\% } \\
\hline \multicolumn{10}{|c|}{ Specimen } \\
\hline \multicolumn{3}{|c|}{1} & \multicolumn{2}{|r|}{2} & \multicolumn{2}{|r|}{3} & \multicolumn{2}{|c|}{4} & \\
\hline $\mathbf{w}$ & 21,5 & \multirow{2}{*}{$-0=63 \mathrm{~mm}$} & 21,6 & \multirow{2}{*}{$0=63 \mathrm{~mm}$} & 21 & \multirow{2}{*}{$0=63 \mathrm{mn}$} & 21,6 & \multirow{2}{*}{$0=63 \mathrm{mn}$} & \\
\hline $\mathbf{t}$ & 6,5 & & 6 & & 6,4 & & 6 & & \\
\hline$\Delta \mathbf{L}$ & $F(N)$ & $\sigma$ & $F(\mathbf{N})$ & $\boldsymbol{\sigma}$ & $F(N)$ & $\boldsymbol{\sigma}$ & $F(N)$ & $\boldsymbol{\sigma}$ & $\varepsilon$ \\
\hline 0,50 & 150 & 1,071 & 350 & 2,692 & 150 & 1,095 & 340 & 2,615 & 0,794 \\
\hline 1,00 & 500 & 3,571 & 800 & 6,154 & 450 & 3,285 & 780 & 6,000 & 1,587 \\
\hline 2,00 & 1250 & 8,929 & 1600 & 12,308 & 1200 & 8,759 & 1600 & 12,308 & 3,175 \\
\hline 2,50 & 1850 & 13,214 & 2150 & 16,538 & 1800 & 13,139 & 2100 & 16,154 & 3,968 \\
\hline 3,00 & 2450 & 17,500 & 3000 & 23,077 & 2400 & 17,518 & 3000 & 23,077 & 4,762 \\
\hline 3,50 & 3250 & 23,214 & 4000 & 30,769 & 3200 & 23,358 & 4100 & 31,538 & 5,556 \\
\hline 4,00 & 4100 & 29,286 & 4250 & 32,692 & 4000 & 29,197 & 4200 & 32,308 & 6,349 \\
\hline 4,50 & 4600 & 32,857 & & & 4500 & 32,847 & & & 7,143 \\
\hline
\end{tabular}


Table 3: Resultsof Tensile Testing of Petungbamboo Wovenstripof $60 \%$ after Immersion in Sulfurwater

\begin{tabular}{|c|c|c|c|c|c|c|c|c|c|}
\hline \multicolumn{10}{|c|}{ Woven Strip 60\% } \\
\hline \multicolumn{10}{|c|}{ Specimen } \\
\hline \multicolumn{3}{|c|}{1} & \multicolumn{2}{|c|}{2} & \multicolumn{2}{|r|}{3} & \multicolumn{2}{|r|}{4} & \\
\hline $\mathbf{w}$ & 20 & \multirow{2}{*}{$\mathrm{L} 0=63 \mathrm{~mm}$} & 21,5 & \multirow{2}{*}{$0=63 \mathrm{~mm}$} & 20 & \multirow{2}{*}{$0=63 \mathrm{mn}$} & 21 & \multirow{2}{*}{$0=63 \mathrm{mn}$} & \\
\hline $\mathbf{t}$ & 6,1 & & 6,3 & & 6,1 & & 6,2 & & \\
\hline$\Delta \mathbf{L}$ & $F(N)$ & $\boldsymbol{\sigma}$ & $F(N)$ & $\sigma$ & $F(N)$ & $\sigma$ & $F(N)$ & $\sigma$ & $\boldsymbol{\varepsilon}$ \\
\hline 0,50 & 200 & 1,639 & 100 & 0,741 & 250 & 2,049 & 150 & 1,154 & 0,794 \\
\hline 1,00 & 650 & 5,328 & 600 & 4,444 & 660 & 5,410 & 620 & 4,769 & 1,587 \\
\hline 2,00 & 1550 & 12,705 & 1550 & 11,481 & 1550 & 12,705 & 1570 & 12,077 & 3,175 \\
\hline 2,50 & 2200 & 18,033 & 2300 & 17,037 & 2200 & 18,033 & 2350 & 18,077 & 3,968 \\
\hline 3,00 & 2950 & 24,180 & 3200 & 23,704 & 2900 & 23,770 & 3250 & 25,000 & 4,762 \\
\hline 3,50 & 3700 & 30,328 & 4150 & 30,741 & 3750 & 30,738 & 4200 & 32,308 & 5,556 \\
\hline 4,00 & 4600 & 37,705 & 4900 & 36,296 & 4650 & 38,115 & 5000 & 38,462 & 6,349 \\
\hline 4,50 & 4800 & 39,344 & & & 4750 & 38,934 & & & 7,143 \\
\hline
\end{tabular}

Based on the results of table 1,2, and 3, can be obtained the maximum strength that can be accepted by petung bamboo wovenstrips as a reinforcement composite epoxy resin can be summarized in table 4 below:

Table 4: Resultsof Tensile Testing of Petungbamboo Wovenstripof 20\%, 40\%, $60 \%$ after Immersion in Sulfurwater

\begin{tabular}{|c|c|c|c|c|c|c|}
\hline \multirow{2}{*}{ No } & \multicolumn{6}{|c|}{ Volume Strip } \\
\cline { 2 - 7 } & \multicolumn{2}{|c|}{$20 \%$} & \multicolumn{2}{c|}{$40 \%$} & \multicolumn{2}{c|}{$60 \%$} \\
\cline { 2 - 7 } & $\boldsymbol{\sigma}$ & $\boldsymbol{\varepsilon}$ & $\boldsymbol{\sigma}$ & $\boldsymbol{\varepsilon}$ & $\boldsymbol{\sigma}$ & $\boldsymbol{\varepsilon}$ \\
\hline 1 & 1,236 & 0,794 & 1,869 & 0,794 & 1,396 & 0,794 \\
\hline 2 & 4,860 & 1,587 & 4,752 & 1,587 & 4,988 & 1,587 \\
\hline 3 & 8,381 & 3,175 & 10,576 & 3,175 & 12,242 & 3,175 \\
\hline 4 & 13,233 & 3,968 & 14,761 & 3,968 & 17,795 & 3,968 \\
\hline 5 & 18,095 & 4,762 & 20,293 & 4,762 & 24,164 & 4,762 \\
\hline 6 & 22,027 & 5,556 & 27,220 & 5,556 & 31,029 & 5,556 \\
\hline 7 & 24,938 & 6,349 & 30,871 & 6,349 & 37,644 & 6,349 \\
\hline 8 & & & 32,852 & 7,143 & 39,139 & 7,143 \\
\hline
\end{tabular}

Based on the results table above can be illustrated by the following figure 1:

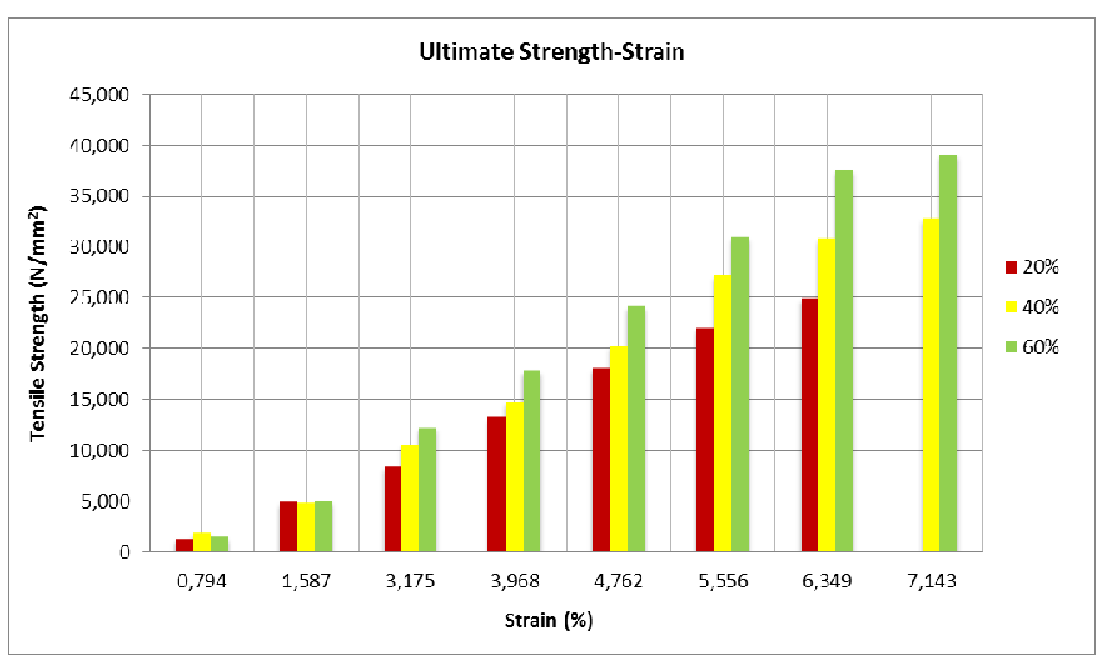

Figure 1: Comparison of Tensile Strength and Strain in Thewoven Stripspetung Bamboo as a Reinforcement Composite Epoxy Resin. 


\section{DISCUSSIONS}

From the table and graph above clearly shows that the strength that occurs in petungbamboo wovenstrips is an immersion in sulfur water as epoxyres in reinforcement at varying wovenstrip volume occurs reinforcement increases with an increase in strain with increasingstrip volume. Wovenstrip at $20 \%$ maximum tensilestrengthreceivedis $24.934 \mathrm{~N} / \mathrm{mm}^{2}$, wovenstrip $40 \%$ of the maximum tensile force is $32.852 \mathrm{~N} / \mathrm{mm}^{2}$ at $60 \%$ wovenstrip maximum tensilestreng this 39.139 $\mathrm{N} / \mathrm{mm}^{2}$.

The more volume is given as a reinforcement wovenstrip composite epoxyresin, the greater the tensile strength can be accepted and conversely. The amount of volume that isused as a reinforcement wovenstrip then its strength is increasing, sopetungbamboocanbeused as an alternative to epoxyresin-efficient amplifier on static and dynamic construction which becomes environmentally friendly composite materials and rawmaterials are easily obtained.

\section{CONCLUSIONS}

Based on the results and the above discussion it can be concluded that woven petung bamboo strip woven immersion with sulfur water for 4 weeks as a reinforcement of epoxy resin can improve the strength of the composite material. Where more and more volume strips were added increasing the tensile strength of the composite material was the highest at $60 \%$ the volume strip $39.139 \mathrm{~N} / \mathrm{mm}^{2}$. Petung is a composite material that can be used as an alternative to epoxy resin composite material reinforcing the strong, the price is cheap, readily available, and environmentally friendly.

\section{ACKNOWLEDGEMENTS}

Thanks to

- Makale Christian College Foundation / Toraja Christian University for supporting the research costs that have been given to me

- Laboratory of Physical Metallurgy HasanuddinUniversity Makassar for assistance during material testing

\section{REFERENCES}

1. Abdurachman, et al. 2015. The Nature of the Composite Beam Combination of Bamboo and Wood. Forest Products Research Journal Vol. No. 20: 33 2, June 15 115-124. ISSN: 0216-4329 Accredited No: 48243 / AU2 / P2MI-LIPI / 0/201. e-mail: man p3hh@yahoo.com

2. Afif, R.F. and Hosta, A. 2013. Effect of Chemical and Immersion Time on the Tensile Strength of Betung Bamboo (Dendrocalamus asper) as a Chemical Preservation Treatment.Department of Materials and Metallurgical Engineering.Industrial Technology Faculty.SepuluhNopember Institute of Technology, Sukolilo Surabaya 60111, Indonesia.Journal of Engineering POMITS Vol. 1, No. 1. (2013) ISSN: 1-6.

3. ASTM. D4762-04, 2005, Guide for Testing Polymer Matrix Composite Materials, American Society for Testing Materials, Philadelphi.

4. Al-Shammari, Mohsin Abdullah, and Muhannad Al-Waily."Theoretical and numerical vibration investigation study of orthotropic hyper composite plate structure." International Journal of Mechanical \& Mechatronics Engineering IJMMEIJENS 14.06 (2014).

5. Gibson, R.F. et al. 1994. Principles of Composite MaterialMechanics. Department of Mechanical Engineering. Wayne State University. Detroit, Michigan. ISBN O-07-023451-5. Copyright @1994 by McGraw-Hill, Inc 
6. Irawan, A.P. and Sukania, I.W. 2013. Compressive Strength and FlexuralMaterial of Epoxy BambooFiber Composites. Journal of Mechanical Engineering, Vol. 14, No. 2, October2013, 59-63 DOI: 10.9744/jtm.14.2.59-63. ISSN 1410-9867

7. Ismail, Mahmud Rasheed, Z. A. A. A. Ali, and Muhannad Al-Waily. "Delamination damage effect on bucklingbehavior of wovenreinforcement composite materials plate." International Journal of Mechanical\&Mechatronics Engineering IJMMEIJENS 18.05 (2018): 83-93.

8. Kadir, Abd. et al. 2014. Effect of Matting Pattern on Tensile Strength and Bending of Bamboo Fiber Strengthened Composites.DYNAMICS Journal of Mechanical Engineering Scientific.Vol. 6, No. 1. November 2014. ISSN: 2085-8817. Date modified 08/02/2016, 15:49.

9. Kesavarao, Yenda, Ch Ramakrishna, and AineelkamalArji. "Stress Analysis of Laminated Graphite/Epoxy Composite Plate Using FEM." International Journal of Mechanical Engineering (IJME) 4 (2015): 5.

10. Medi and Marten, 2011.Study of Geothermal Characteristics Based on the Geochemistry of Macula Hot Springs Wala. Kec.South Sangalla Regency.Tana Toraja Prov. South Sulawesi.URI:http://repository.unhas.ac.id/handle/123456789/458. Hasanudin University.

11. Susanah, Y. and Widayani. 2011. Manufacture and Characterization of Composites UsingCharcoal and Apus BambooFiberwith an Epoxy Resin Matrix.Proceedings of the 2011 National Symposium on Learning and Science Innovation (NSLSI) 2011) 22-23 June 2011. Bandung, Indonesia.

12. Tomar, Archit, and Dheer Singh. "Modelling and Analysis of a Chassis Frame by UsingCarbonFiber and E-Glass Epoxy as Composite Material: A Comparative Study." International Research Journal of Engineering and Technology 3.04 (2016): 2395-0072. 
